health. The splint was applied over the head, neck, and back and at the same time the patient was forbidden to speak. In three days the temperature was normal and the swollen glands disappeared. To-day sulphonamides or penicillin may be employed. At any rate fixation of the head and neck by means of a splint is an excellent treatment of inflammations in the neck region as well as injuries of the hypopharynx and upper parts of the oesophagus. - I am, etc.,

Wroclaw, Poland.

Stanisraw Tuszewski.

\section{Manifestations of Malnutrition}

SIR,-Reference Lieut.-Col. John Huston's letter (Sept. 20, p. 470), I feel he has not grasped the significance of the remarks of Dr. R. G. S. Whitfield and myself as regards epileptiform seizures. These epileptiform seizures were in relatively fit men, both in my case and in three-quarters of Dr. Whitfield's. The varying symptoms, signs, and seizures of the dying emaciated P.O.W. are tragically only too well remembered by most of us. I personally was not referring to these.-I am, etc., York.

LENOX MACFARLANE.

\section{Treatment of Varicose Veins}

SIR,-I was interested to read Prof. A. M. Boyd and Mr. D. J. Robertson's paper on varicose veins (Sept. 20, p. 452). Ligature of the great saphenous vein and all its tributaries is well recognized, but sometimes supplementary ligature of the small saphenous vein should be undertaken at the same time. I remember one case recently when varicosities had developed from both these veins, with apparently no pathological communication. Both showed impulses on coughing, and ligature of the great saphenous alone would not have sufficed to cure the condition. There is no doubt that multiple ligatures as suggested by Prof. Boyd should be more frequently performed than is at present the rule.

The danger of deep thrombosis following injection of sclerosing fluids at the time of operation has always struck me as being very real, and I abandoned this practice some years ago. The extensive thrombosis produced by this method I found truly terrifying, and I am grateful to Prof. Boyd for showing that my fear was more than theoretical. I find that, after satisfactory ligature or ligatures as the case may require, injections may be unnecessary altogether, or at the most one or two may be done when the patient is again ambulant; injection is then much safer. I often think that the minor complaints of humanity are overlooked by research workers, but I think their satisfactory treatment is as important as more spectacular diseases. -I am, etc.,

Newcastle-upon-Tyne.

F. Denis Hindmarsh.

\section{Causalgia of the Face}

Sir,-Mr. C. H. Cullen (Sept. 13, p. 433) draws attention to what he suggests may be a possible fallacy in the reasoning which led me to conclude that in at least some cases of causalgic pain there is a pain pathway by way of the sympathetic chain. He says the stimulus I applied (pressure on, and squeezing of, the superior cervical ganglion) may not have produced sufficient efferent sympathetic impulses to give rise to pain. Mr. Cullen must therefore consider that sympathetic impulses concerned in the maintenance of normal sympathetic tone are greater in number than those produced by such stimulation, as in his view causalgic pain is produced by these normal sympathetic impulses acting on afferent nerve fibres at the site of nerve injury. It seems to me, however, that stimulation such as I carried out would produce a much greater number of nerve impulses than those normally present. Certainly pinching motor fibres produced a greater flow of nerve impulses than are concerned in the maintenance of normal muscle tone. This is so whether the nerve trunk central to the point of stimulation has been blocked with procaine or not.

Mr. Cullen concludes his letter by describing two cases in which he stimulated with a faradic current the peripheral end of a sectioned sympathetic chain without reproducing the causalgic pain that had been present. This is valuable confirmation of my own finding, the only difference between $\mathrm{Mr}$. Cullen's experiment and my own being the nature of the stimulus employed. It is difficult to accept the view that stimu- lation with a faradic current was not sufficient to produce at least as great a discharge of nerve impulse as is required to maintain normal sympathetic tone. Surely a more reasonable conclusion from these observations is the one I drew-that sectioning the sympathetic chain had divided the pain pathway. If there should be any doubt whether such stimulation is adequate it should prove possible by means of electrical recording of action potentials to compare the number of nerve impulses maintaining normal tone with the number produced by such a stimulus. - I am, etc.,

Belfast.

J. A. W. Bingham.

\section{Spontaneous Haemopneumothorax}

SiR,-The two cases of spontaneous haemopneumothorax reported by Dr. J. K. McMyn (Sept. 13, p. 419) are good illustrations of the usual three phases (pain, improvement, signs of internal haemorrhage) in the sequence of events first described by Koral, E. (Amer. Rev. Tuberc., 1936, 33, 185), when intrapleural bleeding complicates spontaneous pneumothorax. I think, however, that it is not sufficiently sealized that the interval between the onset of pnetrmothorax and the occurrence of clear evidence of serious haemorrhage may be as short as a few hours.

The chief danger facing the patient who has sustained a spontaneous pneumothorax is generally stated to be a further escape of air and a valve-like action of a kinked bronchus causing a pneumothorax suffocant. Internal haemorrhage is a rare but equally dangerous and sometimes hardly less dramatic emergency which should be watched for in every patient who suffers a pleuro-pulmonary perforation.-I am, etc.,
Enfield, Middlesex.
C. Allan Birch.

\section{Hypoglycaemia following Partial Gastrectomy}

SIR,-Dr. R. D. Lawrence's letter (Sept. 20, p. 470) calls attention to the fact that in the paper by Prof. Dunlop and myself on hypoglycaemia following partial gastrectomy (Aug. 30, p. 330) no reference is made to his previous artic'e in the Journal $(1936,1,526)$. In it he describes several of the features of the post-operative blood sugar curves which we have since confirmed. His paper was entirly concerned with the hyperglycaemic phase in such curves, whereas we were particularly interested in the subsequent reactionary hypoglycaemia. Thus, in looking up the literature on hypoglycaemia we failed to note his paper on "Glycosuria of the "Lag Storage' Type-an Explanation" (oxyhyperglycaemia), which was actually, however, very germane to our subject. We therefore owe him an apology for our oversight.-I am, etc.,

Edinburgh.

\section{J. A. L. Gilbert.}

\section{The Lazy Eye}

SIR,-One sympathizes with Dr. William Moodie's concern (Aug. 23, p. 310) that the treatment of an amblyopic eye by occlusion of its fellow may result in educational backwardness and even initiate a neurosis. It is true that this treatment must inevitably subject the child to a certain amount of nerve strain and restrict its normal activities, but a grave disservice would be done to children with amblyopia if adverse criticisms of a valuable method of treatment were allowed to pass without further comment.

Dr. Moodie's suggestion that the rational treatment for amblyopia should be "optical" as it is an optical condition cannot be accepted. The essential lesion of true amblyopia lies in the psychological phase of the visual arc, a view that is confirmed by the mode of development by histological studies of amblyopic eyes, and by its response to treatment. There is ample clinical evidence that vision in these eyes will frequently improve, even late in life, under the psychological stimulus of the loss of the fellow functioning eye or following treatment by suggestion.

The statement that treatment by occlusion results in educational backwardness and may initiate neurosis requires qualification. As a group, children with squint show a high incidence of left-handedness and emotional instability, but occlusion cannot be blamed for a state of affairs which exists before the treatment is commenced. Children usually enjoy orthoptic training, and the exceptional case which does not tolerate the psychological strain of occlusion must have the treatment 
modified. The objection regarding education would not arise if amblyopic eyes were treated before serious schooling began, the ideal being before 6 years of age. Unfortunately many children are not brought until later, sometimes not until young adult life, and at this stage the recognition of the existence of three types of amblyopia is a guide to the value of treatment and will avoid useless occlusion and unnecessary nerve strain.

The three types of amblyopia are:

(1) The "purposive" amblyopia associated with concomitant squint, which may be regarded as a deliberate act of suppression designed to avoid the psychic trauma of diplopia.

(2) The "passive" amblyopia resulting from failure to condition in infancy the central pathways subserving macular perception. This form is a legacy of some condition which interfered during the first two years of life with the visual acuity necessary to educate macular function-uncorrected refractive errors, congenital cataracts, infantile keratitis, ophthalmia neonatorum, etc.

(3) "Pseudo"-amblyopia in which, despite a fundus of normal appearance, developmental defects such as macular dysplasia, or acquired defects such as macular haemorrhages at birth, have made central vision impossible. These conditions are frequently termed " congenital " amblyopia and by orthoptists "intractable" amblyopia, but actually are not examples of true amblyopia.

These three types can usually be differentiated clinically, and distress to the chiid can be avoided if their varying response to treatment by occlusion is borne in mind.

Passive amblyopia is most satisfactory to treát, even in adult life, for there is no active desire to suppress and vision rapidly improves. Treatment of the defective vision due to pseudoamblyopia is useless and occlusion should be stopped directly the condition is recognized. It is unfair to a child to force it to depend on an eye which is often anatomically incapable of acquiring even central fixation. The value of treatment by occlusion for purposive amblyopia lies between these two extremes. One is fighting the child's active desire to avoid binocular vision, and each case must be considered on its merits, having regard to the fact that the treatment of the amblyopia is only part of the general plan of treatment for the associated squint. In general, occlusion should be used as a routine up to the age of 12 years and tried in a tentative way after that age.

Dr. Moodie has rightly stressed the importance of not subjecting a child with amblyopia to unnecessary nerve strain, but he must recognize the equal importance of securing where possible some vision for an amblyopic eye. It is the first step towards securing the benefits of binocular vision, and, even more, it may be the means of averting the tragedy of blindness later in life should the vision of the other eye be lost from accident or disease.-I am, etc.,

Southsea, Hants.

W. Hedley Summerskill.

\section{Retained Placenta}

SiR,- Some months ago, and again recently, you published correspondence about retained placenta. On neither occasion was a method mentioned which $I$ have used for the last five years. It was first described to me by A. W. Andison, now of Winnipeg, and is mentioned in the Annual Report of the Liverpool Maternity Hospital for 1941 . Who originated the method I have been unable to discover. I suspect it is so old that no one knows. When a mare "holds her cleanings," it is the practice in some farming communities to attach a piece of lead piping to the cord and to allow the animal to walk about at will. I do not use lead piping; the method as modified by me is to attach to the cord, by means of a length of bandage, a weight of $2 \mathrm{lb}$. $(0.9 \mathrm{~kg}$.). After a few minutes to allow for stretching of the cord the bandage is marked in ink where it passes over the end of the bed. In many cases, after a variable interval, the mark will be found 4-6 in. (10-15 cm.) lower than this, indicating that the placenta is now awaiting expression from the lower segment and upper vagina.

This is an "over the telephone" method. It can be used in desperate cases while the blood loss is being made good by transfusion. It can be used in cases where the general condition has not deteriorated. If the patient is fit but is bleeding, more immediate treatment, either by manual removal or intravenous ergometrine, is to be preferred. The obvious danger of this method is theoretical only. I refer, of course, to inversion of the uterus. The traction is not sufficiently strong to bring about this catastrophe. I suggest that the mechanism by which a successful result is obtained is that the empty lower segment is folded upon itself in a concertina-like manner. Stimulation of the lower segment in this way causes the upper segment to contract and expel the placenta. If the placenta has partly occupied the lower segment, as is often the case when it is retained, this concertina effect should, and in fact does, stop bleeding from the area of detachment.

However the result is produced, it is extremely gratifying to find, after waiting possibly for hours for blood transfusion to render a patient fit for manual removal, that this hazardous procedure is not required. The descent of the mark on the bandage indicates that gentle fundal pressure is all that is necessary. For recording purposes I have called this method "continuous light cord traction."-I am, etc.,

Stockport, Cheshire.

WaLter CALVERT.

\section{Planning and World Population}

SIR,-In his letter (Sept. 6, p. 395) on this subject Dr. E. F. Griffith states: "Now that modern contraceptive methods are so reliable and comparatively cheap, it should be possible, by means of a well-thought-out education policy, to bring a knowledge of these matters to the women of the East." It would be just as logical to state : "Now that motor banditry is so reliable and comparatively safe (vide records of undetected crime), it should be possible, by means of newspaper reports and cinema films and other methods, to bring a knowledge of these matters to the men of the East," because both practices are intrinsically evil-i.e., in the acts themselves and not merely on account of their consequences.

One of man's functions as made known to him by his reason is the continuance of the race, and contraception, by frustrating this function, although using the physical act of sexual intercourse, thereby becomes intrinsically evil, and this applies to each individual contraceptive act.-I am, etc.,

London, W.C.1.

G. E. Paul.

\section{Contact Lenses}

SiR,-As a recent convert to the wearing of Hamblin-Dallos contact lenses, from my own experience I can scarcely agree less with the remarks of Mr. A. Seymour Philps (Sept. 20, p. 469). The sensation of a foreign body beneăth the lids is very soon lost, and I have found that after only a month of systematic and careful conjunctival training I am now able to wear them without embarrassment up to 16 hours, with occasional removal for clearing off epithelial debris and immediate replacement. The secret for complete comfort is the use of a physiological saline eye-bath as part of the daily toilet. As a microscopist these lenses take an invaluable place in my daily work, and the sense of ocular fatigue and lid weariness experienced in my spectacle days is now relegated to past memories.-I am, etc.,

Exeter. Peter Warren.

\section{Salaries of Specialists in N.H.S.}

SIR,- - I cannot think that any difference of opinion which may have arisen over the payment of psychiatrists as compared with physicians and surgeons is due, as Dr. Northage J. de V. Mather suggests in his letter (Sept. 6, p. 398), to fluctuations in the standard of the D.P.M. as opposed to that of the M.R.C.P. and F.R.C.S. I would almost, with respect, suggest that there exists here either a confusion of thought or even a wishful thinking. Surely the D.P.M. is, with many others, a special diploma-no more and no less than that. The M.R.C.P. and the F.R.C.S. are higher qualifications and rank accordingly; they are difficult to obtain - and rightly so-without considerable postgraduate learning and experience, and the whole background which a successful candidate must possess is a wide one.

In my opinion (which I know is shared by many others) the psychiatrist would do well to aim at attaining, in the realm of medicine, something of the standard demanded by the M.R.C.P. before he embarks seriously upon his chosen specialty. There can hardly be any comparison between the M.R.C.P. and the D.P.M. The latter cannot equal (which appears to be Dr. Mather's suggestion) the former, and never was it meant to do so. If the consulting psychiatrist is to rank as does the consulting physician, he should in my view possess both the higher qualification and the diploma of his own specialty.-I am, etc.,

London, W.1. Maurice L. Young. 